\title{
STUDY OF BREAKAGE CURVES IN ULTRAFINE BALL MILL- DRY GRINDING
}

\author{
P. Hari Babu ${ }^{1}$, R. Bhanu Prasad ${ }^{2}$ \\ ${ }^{I}$ P. Hari Babu, Department of Chemical Engineering, RGUKT, Telangana, India \\ ${ }^{2}$ R. Bhanu Prasad, Department of Chemical Engineering, RGUKT, Telangana, India
}

\begin{abstract}
Grinding of an ore assists in liberating minerals from the lumps of primary ore and to facilitate easier transportation / handling in the downstream operations of a hydrometallurgical plant. It is the most energy intensive operation consuming 25-30\% of the total energy input to the plant and thereby bears equivalent operating cost. Aim of the present study is to study the kinetics and the breakage mechanism of different types of feed by ultrafine dry grinding. The results of this experiment shows the change in the specific rate of breakage of material with respect to different size fractions and the energy requirement for different size fractions of feed. In comparison with rotary drum ball mill this consumes more energy for dry (feed) grinding.
\end{abstract}

Key Words: Ultrafine Grinding, Breakage Curve, Size Fraction

\section{INTRODUCTION}

Grinding is a secondary mechanical unit operation which is used to reduce the material into powder by impact and attrition forces. Sometimes compression may act between the balls and material. The product from a crusher is often fed to a grinder, reducing to finer products.

Ultrafine grinding one of the mechanical unit operation which is used to reduce the material into very fine particles and the range of product is in micro meters. Usually the feed for the ultrafine grinder is the product of the ball mills. The main principle used in the ultrafine ball is attrition and impact forces between the material, medium and between the particles.

Gao et al $[\mathrm{I}]$ found that by increasing the power the size reduction was accelerated dramatically with small changes to the energy efficiency of the process. Shinohara et al. [2] investigated the fine grinding characteristics of hard materials by means of the attrition mill. Schwarz and Seebach , (3) reported the ultrafine grinding requires $30 \%$ to $50 \%$ of the energy of conventional ball mills for the same size reduction task on cement clinker.

Bowdish (4) studied the effect of change in ball size, for the same total weight of balls, on the kinetics of batch grinding. He confirmed that the rate equations which described the breakage process were first order and measured the effect of change in ball size on the rate constants for different sizes of limestone. He detected some deviations from first order kinetics and observed that the size distribution of the undersize material, formed by progressive breakage, had an influence on the rate constants.

Hukki (5) has shown that the increase in surface area of cement per unit of energy input decreases as the material becomes very fine and, eventually, further grinding produces virtually no increase in surface area. This phenomenon has been variously explained as due to the reforming of particles by a briquetting action, coating of the bails with an adherent layer of soft powder, a cushioning action of the bed of fine powder, or even a very high strength of small particles.

Lichter et al, (6) investigated that in ball mills, motion is imparted to the media by rotation of the mill shell. The speed of rotation is limited by the critical speed at which the media would centrifuge. Ball mills use steel media of the range 20 to $50 \mathrm{~mm}$ for finer grind sizes. Ball mills have the disadvantages of poor energy efficiency, high sliming, large footprint and contamination of the product with steel media when compared to stirred mills.

\section{EXPERIMENTAL}

\subsection{Materials}

Solid red brick was taken as the feed and was subjected to jaw crushing and later into ball mill grinding machine. Later the grinded ore of brick powder was classified into various size fractions by dry sieving using the gyratory motion. The sieve fractions used in the present study for ultrafine grinding are given in Table 2.1.

Table -2.1: Different sieve fractions used for ultrafine dry grinding experiment same of the Table

\begin{tabular}{|l|l|}
\hline Sieve size & Weight $(\mathrm{g})$ \\
\hline$-100+140$ & 80 \\
\hline$-170+200$ & 70 \\
\hline$-230+270$ & 80 \\
\hline$-325+400$ & 70 \\
\hline
\end{tabular}




\subsection{Experimental Set Up}

\subsubsection{Ultrafine Ball Mill}

Ultrafine ball mill equipped with Nob to adjust the rpm and time required to grind the material. $50 \mathrm{ml}$ of bowl $/$ pan is used as a container for the material to be grinded. Mechanical clamp are provided to hold the bowl so that the grinding material is intact so that spillage of material can be constrained. The below figure depicts the laboratory ultrafine ball mill.

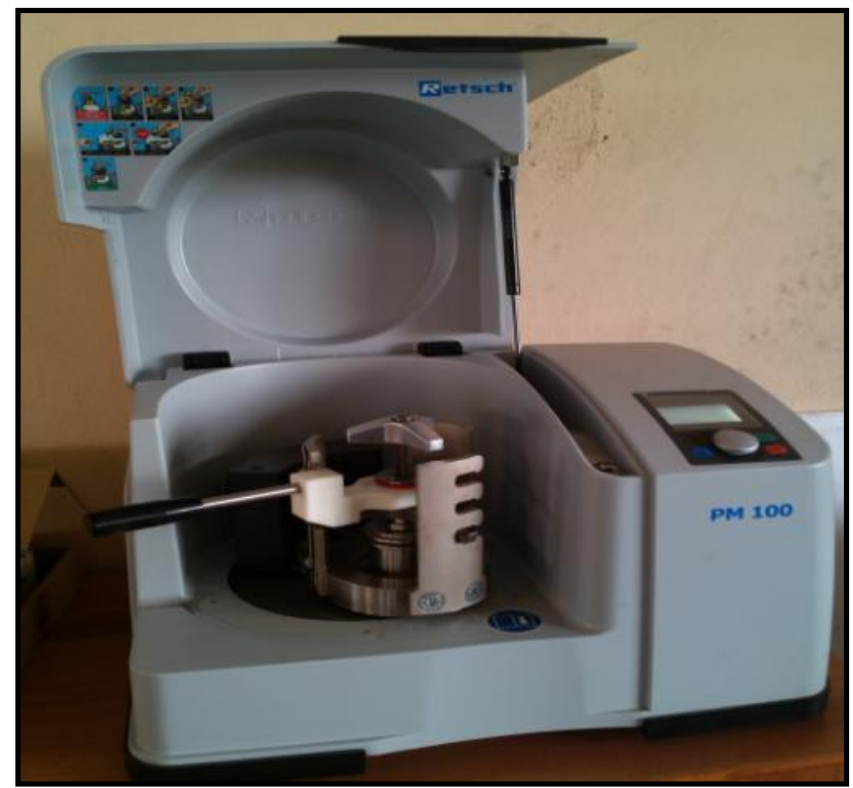

Fig -1: Ultrafine ball mill

\subsubsection{Sieve Shaker}

Sieve shaker comprising a series of stacked sieves maximum up to 400 micro meters, having gyratory motion control and holding rods to hold the sieves.

\section{EXPERIMENTAL METHODOLOGY}

\subsection{Sample Preparation}

Brick powder was grounded and sufficient amount of material as described above of each 4 different size fractions $-100+140,-170+200,-230+270,-325+400$ were obtained by dry sieving of the above material.

\subsection{Grinding Procedure}

Each fraction was ground individually and batch wise for short time periods as shown in Table no. 3.2. The grinded product was withdrawn from the ultrafine ball mill at the end of each time period, sieved on lower mesh and the \% retained on the sieve was noted.

Table -3.2: Grinding time periods at which $\%$ retained on lower mesh was determine

\begin{tabular}{|l|l|l|l|l|l|}
\hline $\begin{array}{l}\text { Grinding } \\
\text { time(min) }\end{array}$ & 0 & 3 & 6 & 9 & 12 \\
\hline
\end{tabular}

\section{RESULTS}

Results of experiments carried out are given in Table no. 4.1. $\mathrm{W}_{1}(0)=$ fraction of weight retained on lower mesh at time 0 min. $\mathrm{W}_{1}(\mathrm{t})=$ fraction of weight retained on lower mesh at time t. Suffix 1 denotes the size fraction. Four sieve fractions were studied in the present investigations.

Table 4.1: Results of grinding of $-100+140$ mesh size

\begin{tabular}{|l|l|l|l|}
\hline time & $\begin{array}{c}\text { Wt retained } \\
\text { on lower } \\
\text { sieve }\end{array}$ & $\frac{\mathrm{W} 1(\mathrm{t})}{\mathrm{W} 1(0)}$ & $\log \frac{\mathrm{W} 1(\mathrm{t})}{\mathrm{W} 1(0)}$ \\
\hline 0 & 30 & 1 & 0 \\
\hline 3 & 27 & 0.9 & -0.05 \\
\hline 6 & 26 & 0.87 & -0.06 \\
\hline 9 & 24 & 0.8 & -0.10 \\
\hline 12 & 22 & 0.73 & -0.14 \\
\hline 15 & 20 & 0.67 & -0.17 \\
\hline
\end{tabular}

The results are plotted in Fig no. 4.1 to determine specific breakage rate of grounded material.

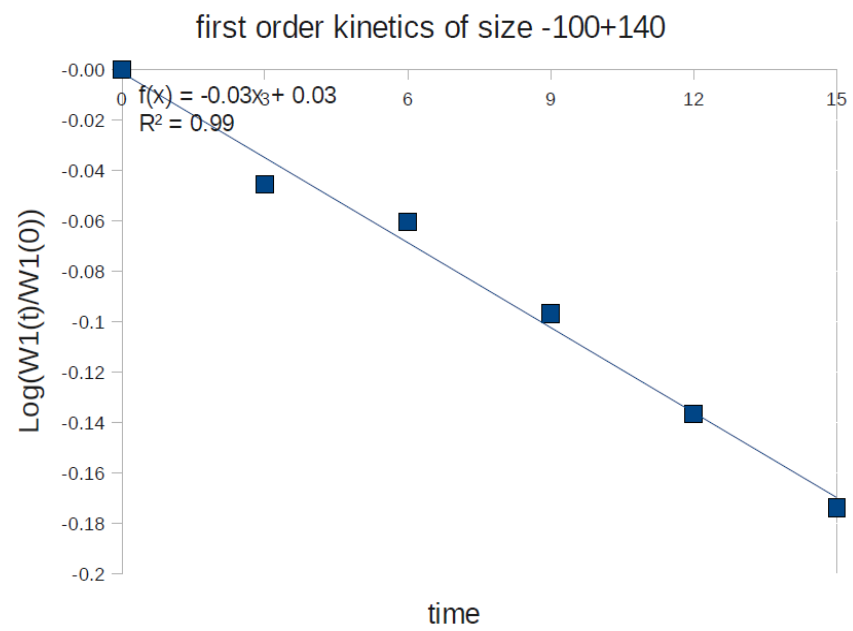

Chart no.4.1 First order plot for batch grinding of size fraction $-100+140$

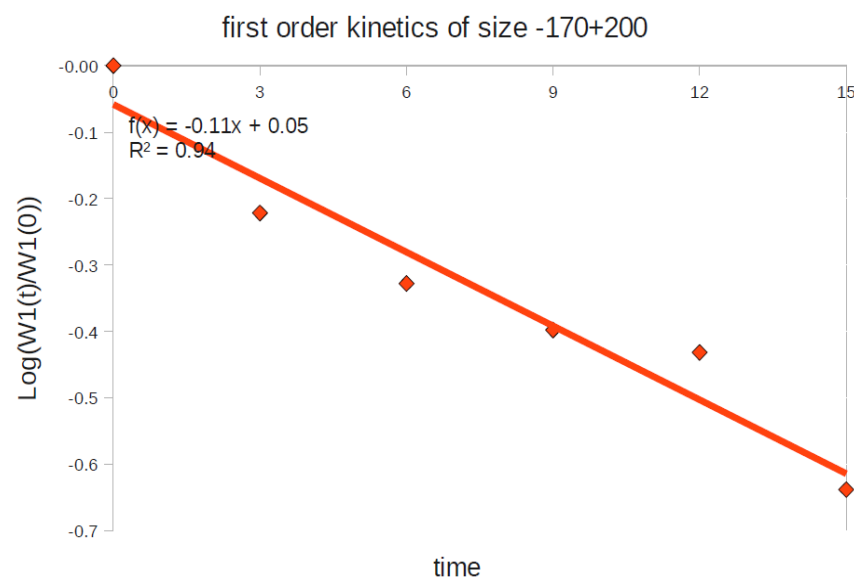

Chart no.4.2 First order plot for batch grinding of size fraction $-170+200$ 


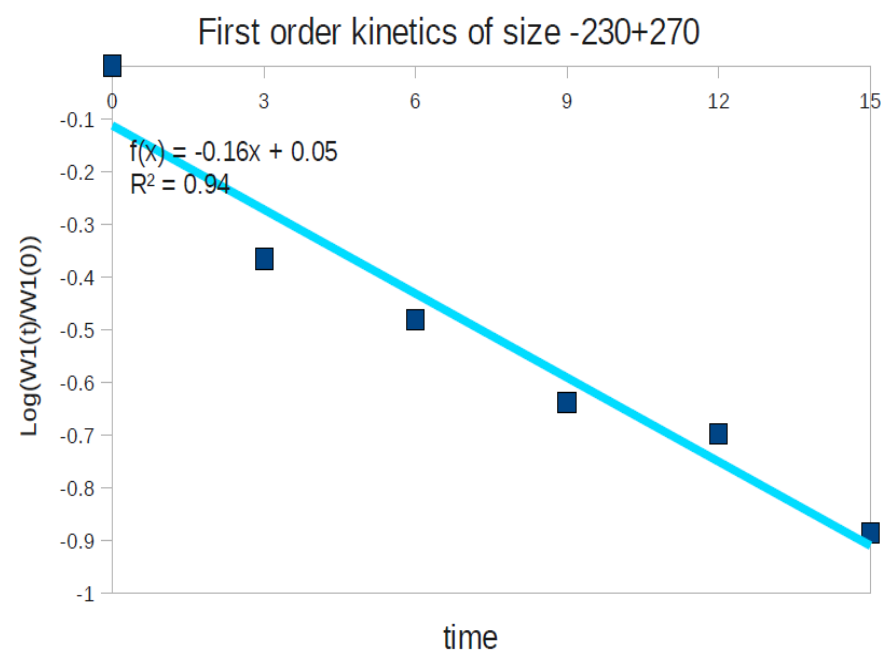

Chart no.4.3 First order plot for batch grinding of size fraction $-230+270$

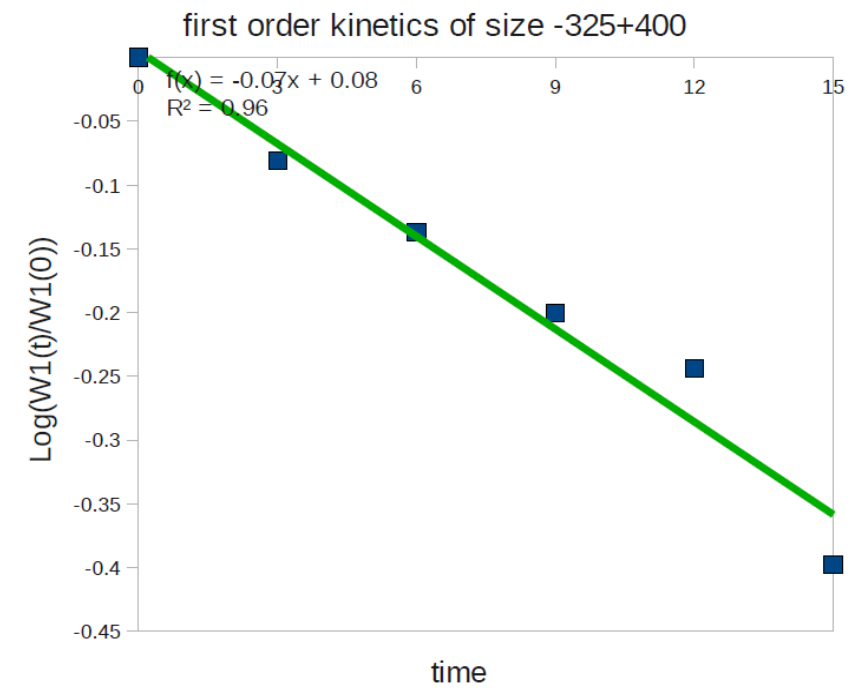

Chart no.4.3 First order plot for batch grinding of size fraction $-325+400$

The specific breakage rates determined in all the above combinations of grinding are summarized in Table no. 4.5

\begin{tabular}{|l|l|l|l|l|}
\hline $\begin{array}{l}\text { Size } \\
\text { fraction }\end{array}$ & $\begin{array}{l}\text { Diameter } \\
(\mathrm{dp})\end{array}$ & $\mathrm{Si}$ & $\log (\mathrm{dp})$ & $\log (\mathrm{Si})$ \\
\hline$-100+140$ & 0.13 & 0.03 & -0.89 & -1.48 \\
\hline$-170+200$ & 0.08 & 0.11 & -1.09 & -0.96 \\
\hline$-230+270$ & 0.06 & 0.16 & -1.23 & -0.80 \\
\hline$-325+400$ & 0.08 & 0.07 & -1.09 & -1.15 \\
\hline
\end{tabular}

The results of specific rate of breakages of above experiments are plotted in the Fig no. 4.5

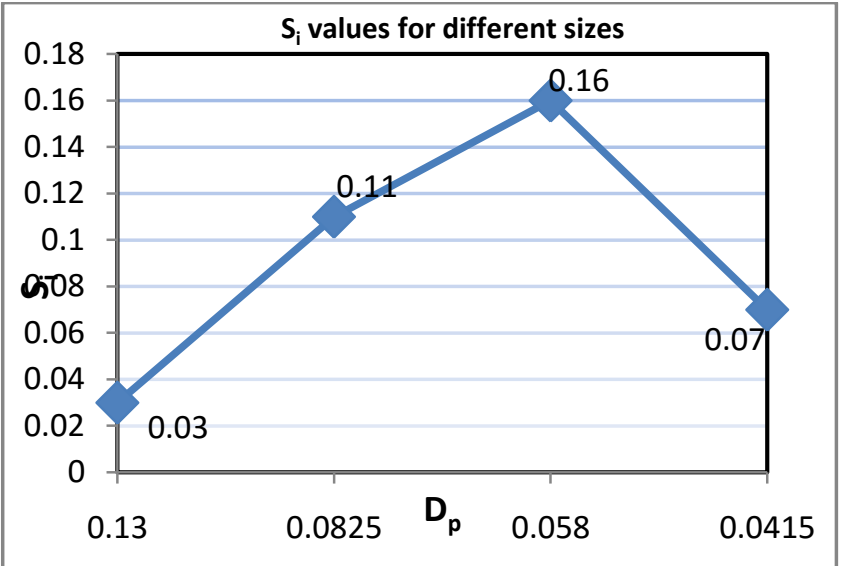

Chart no.4.5 Selective breakage indices for different grounded ores.

\section{CONCLUSIONS}

Dry grinding of the given brick powder follows the first order kinetics there by increasing the specific rate of breakage values as we increasing the feed size. The first ordered kinetics follows the equation as shown below.

$$
\frac{W 1(t)}{W 1(0)}=e^{-S i . t} \leftrightarrow \log \left(\frac{W 1(t)}{W 1(0)}\right)=- \text { Si.t }
$$

Where,

$\mathrm{w}_{1}(\mathrm{t})$ is the weight fraction of mill hold up at time $\mathrm{t}$.

$\mathrm{S}_{\mathrm{i}}$ is proportionality constant and is called specific rate of breakage with units of time ${ }^{-1}$.

The selection function for each size class, $\mathrm{Si}$, presents a proportionality relationship with the power consumed by the grinding as per the below equation

Where,

$$
\mathrm{S}_{\mathrm{i}}=\mathrm{S}_{\mathrm{i}}^{\mathrm{E}}\left({ }^{\mathrm{P} / \mathrm{H}}\right)
$$

$\mathrm{Si}\left(\mathrm{h}^{-1}\right)$ is the selection function for each size class,

$\mathrm{SiE}(\mathrm{t} / \mathrm{kWh})$ is the energy specific selection function,

$\mathrm{H}(\mathrm{t})$ is mill holdup and $\mathrm{P}(\mathrm{kW})$ is net grinding power.

When we plot a graph between $\log (\mathrm{W} 1$ (t)/W1 (0)) vs. grinding time, the results shows straight lines passing through the origin and slope of the curve at any time is same which inferences that the data follows the first order kinetics from which the Slope of the curve can be evaluated which in turns determines the specific rate of breakage (Si). From the first order kinetics we can easily find out $\mathrm{Si}$ values and it is easy to study the relationship between the energy consumption of the mill which is also given as per the bond's work index law.

$$
\frac{E}{\text { unit mass }}=W i\left(\frac{1}{\sqrt{D p}}-\frac{1}{\sqrt{D f}}\right)
$$

Where,

$\mathrm{Wi}=$ work index of the material.

$\mathrm{Dp}=$ volume mean diameter of the product.

Df $=$ diameter of the Feed. 


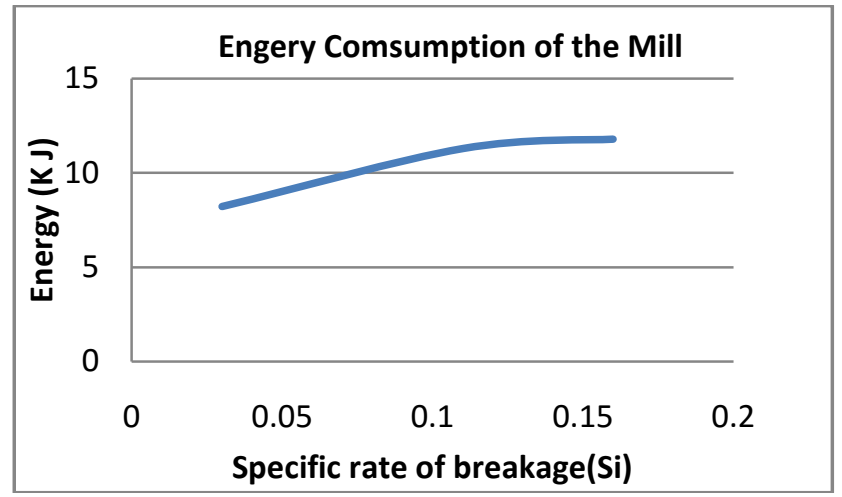

As the particle size decrease more energy is required to grind the material, specific rate of breakage is increases after some particular size specific rate of breakage is decreasing because as the particles are become small and small no grinding is taking place. Specific rate of breakage is mainly depends on the how fast the material can break.

We can also observe from the experimental work that there is a decrease in specific rate of breakage after some particular size fraction or threshold size fraction

In the future scope of work we can draw a comparison between the dry grinding and wet grinding keeping the same parameters and provide constructive data of consumption of energy.One should take care of the product during the very fine product size as it is very difficult to sieve due to plugging of particles and loss of product also accounts.

\section{ACKNOWLEDGEMENT}

We wish to express our gratitude to the entire faculty members of Chemical Engineering and the lab assistants, RGUKT-BASAR involved in the completion of this work throughout and making it successful.

\section{REFERENCES}

[1]. Gao, M., Young, M. \& Allum, P., 2002. IsalMill Fine Grinding Technology and its Industrial Application at Mount Isa Mines, Proceedings of the $34^{\text {th }}$ Annual Meeting of the Canadian mineral processors, Ottawa, Canada.

[2]. SHINOHARA K., GOLMAN B., UCHIYAMA T., OTANI M., 1999, Fine-grinding characteristics of hard materials by attrition mill, Powder Technology 103, 292-296

[3]. Schwarz, S. and Seebach, M. 1990. Optimization of grinding in high pressure grinding rolls and downstream ball mills, $7^{\text {th }}$ European Symposium on Comminution, Ljubljana, vol. 2, pp. 777-788

[4]. F. W. Bowdish,"Theorectical and experimental studies of the Kinectics of Grinding in Ball mill," Trans. AIME, 217, 194-202(1960)

[5]. R. T.Hukki and I. G. Reddy, Dechema Monograph., 57(1967) 313.

[6]. Lichter, J.K.H. \& Davey, G., 2002, Selection and sizing of ultrafine and stirred Grinding Mills, Mineral Processing Plant Design, Practice, and Control
Proceedings, SME, USA, pp. 783-800.

[7]. R. Hogg Breakage mechanisms and mill performance in ultrafine grinding.

[8]. RICHARD JOHN TAMBLYN analysis of energy requirements in stirred media mills.

\section{BIOGRAPHIES}

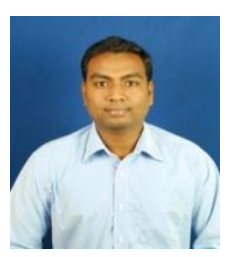

Mr.P Hari Babu accomplished his postgraduation from IIT Madras and having more than 4years of teaching experience. Currently working in RGUKT-Basar Campus, Key working areas- CFD, Mass and Heat transfer.

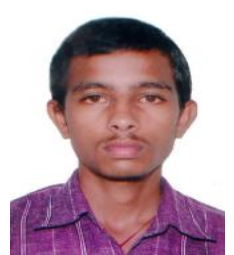

Mr. Rayala Bhanu Prasad completed his graduation with specialization in Unit Operation Engineering from RGUKT University, Basar. Currently working as Process Engineer at Amararaja Batteries Ltd., Tirupati, AP 